\title{
School Violence and Adolescent Suicide: strategies for effective intervention
}

\author{
KATHRYNE M. SPEAKER, The College of New Jersey, USA \\ GEORGE J. PETERSEN, University of Missouri-Columbia, USA
}

\begin{abstract}
The public school system in the United States has always presented itself as representing the hallmarks of vital socialization, equality in education, hope for the future and sense of community. This picture has changed drastically in the past 20 years. Chaos seems to be replacing community. This fact is only too apparent when we read recent accounts of the tragedies that have unfolded in the past 3 years in Pearl, Mississippi, West Paducah, Kentucky, Jonesboro, Arkansas, Springfield, Oregon or Littleton, Colorado. As a result of the deteriorating social environment and a significant growing fiscal crisis faced by our nation's schools, children are encountering substantial hurdles on their journey toward responsible adulthood. Two current trends, which are negatively affecting students' educational experience and quality of life are violence and suicide. Juvenile violence and suicide are becoming increasingly commonplace across the United States. In 1994, an average of one young person aged 24 and younger killed themselves every 1 hour and 39.6 minutes. The number of incidents of violence and the severity of these acts have also dramatically increased over the past 5 to 7 years. This article addresses the causes and strategies for prevention of school violence and adolescent suicide and delineates a holistic integrated prevention model.
\end{abstract}

\section{Introduction}

The public school system in the United States has always represented itself as being the hallmark of vital socialization, equality in education, hope for the future and sense of community. This picture has changed drastically in the past 20 years. Chaos seems to be replacing community (Lantieri \& Patti, 1996). Juvenile violence and suicide are becoming increasingly commonplace and occurrences of both phenomena cross all economic, social and ethnic lines. While the increasing tide of juvenile violence in the streets is alarming, it is particularly problematic because of its insidious encroachment into the public school system (Sautter, 1995). Violence disrupts normal school operation, students do not learn and teachers cannot teach. It degrades the quality of life and the education of children, and it forces some schools to allocate many of their already limited resources to security and prevention measures (Berliner \& Biddle, 1995).

The causes of violence in our culture are extremely complicated. Literature in the area has pointed to the complex interaction between poverty, racism, drugs and alcohol, the loss of employment, inadequate hand gun regulation, lack of personal opportunity and responsibility, disinvestment in schools and family violence as all playing a crucial role in America's culture of violence (Hranitz \& Eddowes, 1990; Prothrow-Stith, 1994). In a recent survey of school administrators, over $50 \%$ of the respondents felt that lack of parental involvement was the single most important contributor to school violence (Stephens, 1994). Societal changes, the breakdown of family relationships and violent role models in the media have also been cited as contributing factors to school violence (MetLife, 1994).

The American family structure has shifted away from the idealized two-parent family with dad working and mom at home with the children. According to the US Department of Health and Human Services (1993) report, Child Health USA ' $92,75 \%$ of all mothers of school-age children are in the labor force, up from about half in 1970. One in four children live in families with only one parent, more than double the rate of two decades ago. A 1992 Children Defense Fund Report indicated that more than 14 million children-22\% of all children—live in families below the poverty line, the highest number and rate since 1965. 
As a result of the deteriorating social environment and growing fiscal crisis, many children face substantial hurdles on their journey toward adulthood. Dryfoos (1994) refers to these barriers as the 'new morbidities' - unprotected sex, drugs, violence, and depression ....in contrast to the 'old morbidities' — chronic diseases, nutritional deficiencies, acne and infestation of head lice. Needless to say, these 'new morbidities' also create significant problems for schools.

Today's schools feel pressured to feed children; provide psychological support services; offer health screening; establish referral networks related to substance abuse, child welfare, and sexual abuse; cooperate with the local police and probation officers; add curricula for prevention of substance abuse, teen pregnancy, suicide, and violence; and actively promote social skills, good nutrition, safety, and general health. (Dryfoos, 1994, p. 5)

The connection between violence and suicide in the United States is alarming. Research has demonstrated that many of the same negative societal changes are also the components identified as significant contributors to adolescent suicide(McGuire \&Ely, 1984).In1994,an average of one young person aged 24 or younger killed themselves every 1 hour 39.6 minutes (NCHS, 1997). The increase in the number of firearms in this country is important in both violence and suicide of youth. NCHS data also show that $67.5 \%$ of the total suicides of the young in 1994 were by firearms, and accounted for $96 \%$ of the increase in the overall rate of suicide among persons aged 15-19 from 198095. In 1994 almost 3350 of the suicides aged 15-24 (close to 5000 — total in this age range) were by firearms (NCHS, 1997). We also know, just as violence in the school has increased dramatically, that suicide among adolescents has increased 300\% in the past 30 years (Brent, 1995; Malley et al., 1996). Even with efforts to provide prevention programs, the rate among persons 15-19 years has increased by 23\% and among persons aged 10-14 years by 112\%. For African American males aged15-19 the rate increased 146\% (NCHS, 1997). These rates and numbers are probably low, and in fact the actual rates may be as much as five times higher than these reported rates (Poland, 1989).

For many reasons American schools have not focused adequate attention on either youth violence or suicide. The search for solutions to these problems has generated a collection of approaches that parallel those used by law enforcement personnel to combat violence and crime in United States society (Noguera, 1995).Yet budgetary, scheduling and resource constraints on American education force schools to deal with violence and suicide in a piecemeal fashion, and recent research has shown that this fragmented approach is meeting with little success (Berman \& Jobes, 1995; Petersen et al., 1998).In a recent study, 1200 educators were queried about suicide prevention plans at their school site. Only $20 \%$ indicated that their school had such a plan (see Table I).

The majority of violence prevention programs target the areas of parental involvement, gang activity, drugs and conflict resolution skills and are being piloted in middle schools/junior high and senior high schools with little attention paid to the problem at the elementary level (Stephens, 1994). Other programs, including police partnerships/liaisons, use of advanced technologies (metal detectors, cameras, etc.), removal of lockers (or not installing them), etc., have also been tried, but the results of these efforts have been less than successful in overcoming the enigmatic problem of school violence (Johnson \& Johnson, 1995b). Suicide prevention programs are also often implemented after the fact and deal with post-traumatic reaction rather than prevention. Yet, even after such tragedies, programs are not in place (see Table II). No concentrated effort has been made to determine what programs might effectively prevent violent behavior before it starts (Johnson \& Johnson, 1995a,b).

Programs to combat adolescent suicide have been developed at an even lower rate than those directed toward violence prevention and are often begun as a reactive plan after a suicide has occurred (Kalafat, 1990). The reasons for not having suicide prevention plans include another factor: suicide is a taboo subject at all levels of our society and inherently carries immense shame and feelings of guilt (see Table III). In a 1992 and 1997 Ohio study of 1251 school administrators, teachers and counselors demonstrated that little progress was being made in providing suicide prevention/postvention programs in schools at any level. Even more distressing is that $50 \%$ of middle school teachers and $57 \%$ of the elementary teachers surveyed did not know if their school had even postvention plans and 
that $24 \%$ and $27 \%$ respectively of these teachers were not willing to work in prevention programs, even with training (Wolfle et al., 1998).

Many professionals in the field do recognize, however, that schools must lead in the development and assessment of programs that address the specific needs of adolescents in order to help them with the knowledge, skills and values to make more positive choices in dealing with life and death issues (Allberg \& Chu, 1990; Harding, 1990; Ryerson, 1990; Davis \& Sandoval, 1991; Kalafat \& Ellis, 1994). Rarely is information about the effectiveness of these programs reported in professional journals because of the difficulty in demonstrating that they do prevent adolescent suicide. While empirically based information is beginning to be accumulated, the acquisition of data is difficult because of the small numbers and the lack of documentation of both attempts and completions. The Office of the Inspector General has documented statewide suicide prevention efforts and the American Association of Suicidology has begun an evaluation of model suicide prevention programs across the nation (Malley et al., 1996).

A review of the literature on the subject of teenage suicide would suggest that many of the components in a schoolbased suicide prevention and intervention program parallel the components detailed in an empirically derived model focused on the remediation of school violence in elementary schools (Speaker \& Petersen, 1997). The concepts of proactive, early and inclusive intervention and education are mandated in this violence reduction model. Research in the area of adolescent suicide has indicated that these components are equally essential in a comprehensive and systematic school-based suicide prevention program (Henry, 1996; Wolfle et al., 1998).

\section{Violence-Suicide Reduction Model}

The model presented in this article is based on the conclusions of a national study conducted by the authors of the present paper (Petersen \& Speaker, 1998). The study surveyed teachers, site administrators and district administrators in 15 school districts in12 states. The student populations in the participating districts ranged from fewer than 1000 students to districts with student populations of well over 50,000. A primary focus of the study was to identify education professionals' perceptions of the causes, frequencies and changes in demographics, types and costs associated with violence in P-12 (i.e. primary) settings. In order to identify the underlying elements of the perceived causes for school violence data were subjected to a factor analytic investigation. A principal component analysis using varimax rotation indicated one main factor accounted for over $30 \%$ of the variance. This factor was best described as the general decline of societal/family structures. As the data held one main factor, this analysis was followed up by a principal components analysis using an oblique rotation. This data indicated three to six factors as possible using the eigen value rule of one and the scree test. These factor models were investigated, with the fivefactor solution making the most sense rationally. The five factors seen as contributing most significantly to school violence were:(1) a decline in the family structure;(2) a lack of school resources or skills to deal with violence; (3) the breakdown in moral/ethical education of youth; (4) family violence combined with drug-related factors; and (5) violence in the media. These data confirm previous research which implicated the role of declining societal modeling, media violence and declining family structure as root causes in the escalation of school violence (Met Life, 1994; Prothrow-Stith, 1994). The data further suggest, aside from the previously stated factors, that a lack of skills and resources for professional educators combined with the lack of a moral/ethical education are crucial elements contributing to the serious problems of school violence and adolescent suicide. Studies of adolescent suicide ideation indicate that a lack of effective coping strategies may also be a significant contributor. The model proposed by the authors integrates and proactively addresses each of these factors through five major components or 'pillars'. The need for such intervention at the elementary level is essential to both violence and suicide prevention for at least two reasons. First, studies have demonstrated that prevention models focused on at-risk populations have been shown to be effective when implemented at the preschool/elementary level (Baker, 1992), and data from the authors' study point to the fact that the greatest rise in the frequency of violent acts is at the preschool/elementary level (Speaker \& Petersen, 1997). Suicide rates among those aged 10-14 years are increasing at the highest rate 
during adolescence, indicating that intervention must begin before age 10. Developmentally, it also follows that major coping strategy changes occur early and waiting until high-school age may be too late to make major changes (Nelson \& Crawford, 1990; Wolfle \& Siehl, 1992). An explanation of the model components is shown in Fig. 1.

\section{Family Inclusion}

While schools struggle to implement reactive measures of violence prevention, the data suggest that to successfully address the problem a proactive, comprehensive reorganization of the existing school structure must be undertaken. A key element in this reorganization is the recognition that schools will need to incorporate not only an academic focus for the student but include the family within the educational structure (Dryfoos, 1994). The restructuring of schools should include a new definition of the school as 'town' or 'community center', which supports, includes and engages the entire family in the scope of the educational setting. As the basic structure of the family disintegrates, violence among family members increases and this domestic violence spills into the classroom (Lystad, 1985). This disintegration of family structure is also distinguished as a chronic stressor, one of the categories often related to depression and suicidal ideation (Adams et al., 1996). Other factors directly related to suicide in youth are cognitive deficits that affect ability to solve problems and cope effectively with stressful life events (Ceperich, 1997). These deficits may well be related to normal adolescent cognitive development and need to be considered when developing prevention programs. A new picture of the school must emerge to provide the variety of services that are needed by families and students in order to alleviate incidents of school violence and potential student suicide.

\section{Evolution of Teacher/Administrator Roles}

This component would require schools at the preschool/elementary level to staff their buildings with personnel trained not only in traditional pedagogical methodologies but also in a comprehensive values education (Kirchenbaum, 1992). The role of school counselor should be integral to the entire process of prevention and intervention in the joint program of violence and suicide prevention. All school personnel should be involved in implementing an ethical and social skills curriculum and developing an integrated and inclusive school environment involving the daily modeling of these skills by school personnel for students (Peterson,1997).

\section{Student Success}

The third component of the model involves creating a 'success identity' as referred to by Dinkmeyer and Dinkmeyer (1982) and Glasser (1992). The critical factor in meeting the basic needs of individuals is the creation of individual responsibility that significantly impacts upon personality development. If parents are able to demonstrate and convey a sense of responsibility for themselves as well as in their children, children will develop an integrated concept of self-worth. This ultimately leads to what Glasser refers to as a 'success identity' or Dinkmeyer calls 'significance'. Learning effective ways to satisfy basic needs actively and to effectively cope with life's ups and downs contributes to building positive self-esteem and sense of identity. Adolescent violence and suicide can be viewed as a reaction to unmet physical and emotional needs. The establishment and encouragement of self-esteem in students is an absolute requirement of any successful model since self-esteem is, in itself, a deterrent to participation in violent acts.

\section{Conflict Mediation}

This component of the elementary model does not suggest that there is one specific program of mediation that should be implemented in every classroom. Rather, this component emphasizes that the teaching of some form of empirically field-tested conflict mediation, negotiation procedures and constructive resolution skills should be included in the curriculum of every classroom. As Johnson and Johnson (1995a, 1995b) have repeatedly suggested, the norms, values and culture of a school should promote negotiation and mediation procedures by including classroom lessons on improving communication skills, ways to control anger, appropriate assertiveness, problemsolving skills, perspective-taking, creative thinking and other related interpersonal and small-group skills. Educators 
should also be trained to include the pedagogy of these skills at the earliest educational stages in order to achieve the best results.

This component of conflict mediation should also mirror a current trend in the reorganization of school leadership structures, which advocates collective leadership by both administrators and teachers. The methodology of this system promotes an environment that allows these various groups to meet, discuss, gather, analyze and make decisions regarding resolution of conflict at all levels (Speaker \& Petersen, 1997).

\section{Media Intervention}

There have been numerous conclusive studies that indicate a causal relationship between television violence and actual violence. Regardless of whether the relationship has a direct correlation, educators should address the power of the media when discussing the subject of school violence. Teachers must be equipped to deal with the influences children are exposed to outside the classroom and to be aware that non-attention to media issues is translated by children as acceptance of the violence that they see, hear and live with on a daily basis. There are certain inclusive strategies that every teacher should implement in the classroom. These key elements include creating a safe classroom atmosphere; planning a curriculum which presents alternative reading material that meets each child's developmental needs and allows for the resolution of personal and ethical questions; communicating with children in the classroom while creating the opportunity to make informed choices; and reaching out to parents to involve them in discussions and decisions concerning family choices for viewing, listening and reading (Levin \& Carlsson-Paige, 1995). The influence of the media in the lives of children is pervasive. As Healy (1990) states, schools will have to assume a more positive and educational role in guiding children who are 'visually vulnerable' in analysis and evaluation of media content (p.320). Visual literacy must now be taught in addition to print literacy (Greenfield, 1984). Teaching children to evaluate critically the violence they see on a screen teaches them to interact with their viewing choices and evaluate the impact of those choices on their own lives.

\section{Conclusion}

The search for effective solutions to the problems of violence and suicide will require vigilance on the part of practitioners and more intensive and integrated research on the part of university and educational researchers. The suggestions and ideas presented in this article are not conclusive, yet they compare the documented similarities of violence and suicide. The intention of this article is to focus the reader's attention on the significance and rapid increase in school violence and suicide among our nation's school population. Using a holistic and inclusive model, suggestions for the reduction and remediation of these two phenomena have been presented.

\section{REFERENCES}

ADAMS, D., OVERHOLSER J., SPIRITO,A. (1996) Suicide attempts and stressful life events, The Prevention Researcher, 3(3), pp. 5-8.

ALLBERG, W. \& CHU, L. (1990). Understanding adolescent suicide: correlates in a developmental perspective, School Counselor, 37, pp.343-349.

BAKER, S. (1992) School Counseling for the Twenty-First Century (New York, Merrill).

BERLINER, D.C. \& BIDDLE, B.J. (1995) The Manufactured Crisis: myths, fraud and the attack on America's public schools (Reading, MA, Addison-Wesley). 
BERMAN, A.L. \& JOBES, D.A. (1995) Suicide prevention in adolescents (age 12-18), Suicide and Lifethreatening Behavior, 25(1).

BRENT, D.A. (1995) Risk factors for adolescent suicide and suicidal behavior: mental and substance abuse disorders, family environmental factors, and life stress, Suicide and Life-threatening Behavior, 25(Suppl.), pp.5263.

CEPERICH, S. (1997) Coping interventions for high school-based suicide prevention (high schools at risk), PhD thesis, Arizona State University.

CHILDREN DEFENSE FUND REPORTS (1992) Child Poverty hits 25-year High, Growing by Nearly 1 Million Children in 1991, 13(12), p. 2.

DAVIS, J. \& SANDOVAL, J. (1991) Suicidal Youth (San Francisco, CA, Jossey-Bass).

DINKMEYER, D. \& DINKMEYER, D. (1982) Developing Understanding of Self and Others, DUSO 1 Revised, DUSO 2 Revised (Circle Pines, MN, American Guidance Service).

DRYFOOS, J. (1994) Full Service Schools: a revolution in health services for children, youth and families (San Francisco, CA, Jossey-Bass).

GLASSER, S. (1992) Violence in schools, Congressional Quarterly, pp. 787-802.

GREENFIELD, P. (1984) Mind and Media (Cambridge, MA, Harvard University Press).

HARDING, S.(1990) Child suicide: a review of the literature and implications for school counselors, School Counselor, 37, pp. 328-335.

HEALY, J. (1990) Endangered Minds (New York, Simon \& Schuster).

HENRY, C.(1996) A human ecological approach to adolescent suicide, Prevention Researcher, 3(3), pp.5-8.

HRANITZ, J.R. \& EDDOWES, E.A. (1990) Violence: a crisis in homes and schools Childhood Education, 67(1), pp.4-7.

JOHNSON, D. \& JOHNSON, T. (1995a) Why violence prevention programs don't work and what does, Educational Leadership, 52(5), pp.63-68.

JOHNSON, D. \& JOHNSON, T. (1995b) Reducing School Violence through Conflict Resolution (Alexandria, VA, Association for Supervision and Curriculum Development).

KALAFAT, J. (1990) Adolescent suicide and the implication for school response programs, School Counselor, 37, pp. 343-349.

KALAFAT, J. \& ELIAS, M. (1994)An evaluation of a school-based suicide awareness intervention, Suicide and Life-Threatening Behavior, 24(3), pp.224-233.

KIRSCHENBAUM, H. (1992)A comprehensive model for values education and moral education, Phi Delta Kappan, 73(10), pp.771-776.

LANTIERI, L. \& PATTI, J. (1996) The road to peace in our schools, Educational Leadership, 54(1), pp.28-31. 
LEVIN, D.E. \& CARLSSON-PAIGE, N. (1995)The mighty morphin power rangers: teachers voice concern, Young Children, 50(6), pp. 67-72.

LYSTAD, M. (1985) Innovative mental health services for child disaster victims, Children Today, 14, pp.13-17.

MALLEY, P., KUSH, F. \& BOGO, R. (1996) School-based suicide prevention and intervention programs, Prevention Researcher, 3, pp. 9-11.

MCGUIRE, D. \& ELY, M. (1984) Child suicide, Child Welfare, 1, pp. 17-26.

MET LIFE (1994) The Metropolitan Life Survey of the American Teacher 1994. Violence in America's public schools: the family perspective (Metropolitan Life Insurance Company).

NATIONAL CENTER FOR HEALTH STATISTICS (1997) Advance report of final mortality statistics, 1994, NCHS Monthly Vital Statistics Report, 45(3, Suppl.), pp. 63-80.

NELSON, R. \& CRAWFORD, B. (1990) Suicide among elementary school-aged children, Elementary School Guidance and Counseling, 25, pp. 123-128.

NOGUERA, P.A. (1995) Preventing and producing violence: a critical analysis of responses to school violence, Harvard Educational Review, 65(2),pp. 189-211.

PETERSEN, G.J. (1997) Looking at the big picture: school administrators and violence reduction, Journal of School Leadership,7,(5), pp.456-479.

PETERSEN, G.J., PIETRZAK, D. \& SPEAKER, K.M. (1998) The enemy within: a national study on school violence and prevention, Urban Education, 33(3), pp.331-359.

POLAND, S. (1989) Suicide Intervention in Schools (New York, NY, Guilford Press).

PROTHROW-STITH, D. (1994) Building violence prevention into the curriculum: a physician-administrator applies a public health model to schools, School Administrator, 4(51), pp. 8-12.

RYERSON, D. (1990) Suicide awareness education in schools: the development of a core program and subsequent modifications for special populations or institutions, Death Studies, 14, pp.371-390.

SAUTTER, R. (1995)Standing up to violence, Phi Delta Kappan (Special Report), Phi Delta Kappan, 76, pp. k1k2.

SPEAKER, K.M. \& PETERSEN, G.J. (1997) An empirically based prevention model of school violence, Journal of Southeastern Regional Association of Teacher Educators, 6(2), pp. 3-8.

STEPHENS, R.D. (1994) Gangs guns and school violence, USA Today, 122(2584), pp.29-32.

US DEPARTMENT OF HEALTH AND HUMAN SERVICES.(1993) Child Health USA '92 (Washington, DC,US Government Printing Office).

WOLFLE, J. \&SIEHL, P. (1992) The role of school and family in the prevention of adolescent suicide. Paper presented at the Annual Association of Teacher Educators, Orlando, Florida.

WOLFLE, J.,MERTLER, C., \& HOFFMAN, J. (1998) Do increasing adolescent suicide rates result in increasing prevention/postvention programs in Ohio school? Research paper presented at the annual conference of the Midwestern Educational Research Association, Chicago, ILL, October. 


\section{Figures \& Tables}

TABLE I. Frequencies and percentages of the availability of school suicide prevention program*

\begin{tabular}{lccc}
\hline & Yes & No & Don't Know \\
\hline Does your school have a suicide prevention program? & $244(19.5 \%)$ & $557(44.5 \%)$ & $450(35.9 \%)$ \\
\hline *Numbers in this table are based on frequency counts for each response $(N=1251)$. &
\end{tabular}

TABLE II. Frequencies and percentages of responses of individuals on the development of a postvention program*

\begin{tabular}{lccc}
\hline & No & Don’t Know & Total \\
\hline Should your school develop a postvention program? & 203(16.2\%) & 222(17.7\%) & 425(33.9\%) \\
\hline *Numbers in this table are based on frequency counts for each response. Percentages do not equal100\% because not \\
all participants responded this question $(N=1251)$.
\end{tabular}

TABLE III. Frequencies and percentages of reasons given for not having a suicide prevention program in school*

\begin{tabular}{|c|c|c|c|c|c|c|}
\hline $\begin{array}{c}\text { Suicide } \\
\text { prevention } \\
\text { plan }\end{array}$ & No money & $\begin{array}{l}\text { Community } \\
\text { opposition }\end{array}$ & $\begin{array}{l}\text { Do not know } \\
\text { the reason }\end{array}$ & $\begin{array}{c}\text { No one to run } \\
\text { program }\end{array}$ & $\begin{array}{c}\text { Gives } \\
\text { students the } \\
\text { idea }\end{array}$ & Not necessary \\
\hline & $\begin{array}{c}130 \\
(10.3 \%)\end{array}$ & $\begin{array}{c}24 \\
(1.9 \%)\end{array}$ & $\begin{array}{c}289 \\
(23.1 \%)\end{array}$ & $\begin{array}{c}88 \\
(7.0 \%)\end{array}$ & $\begin{array}{c}32 \\
(2.5 \%)\end{array}$ & $\begin{array}{c}50 \\
(3.9 \%)\end{array}$ \\
\hline
\end{tabular}

*Numbers in this table are based on frequency counts for each response. Percentages do not equal $100 \%$ because not all participants responded this question $(N=1251)$. 


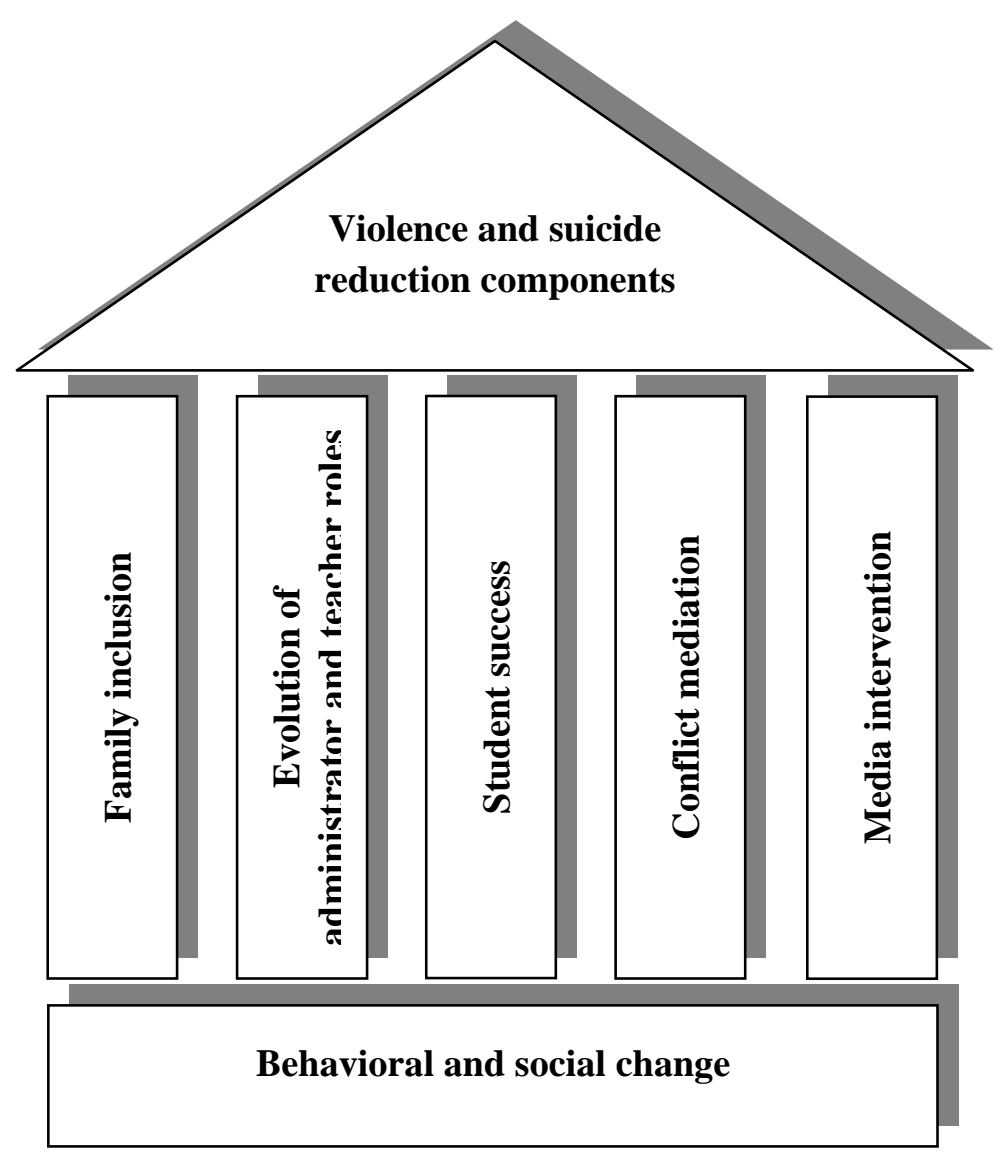

FIG. 1. Model for violence and suicide reduction. 